\title{
Evaluation of Well-Type Chamber Calibration Factor for Measurement of Ir-192 Brachytherapy Source Over 10 Institutions
}

\author{
Assef Firnando Firmansyah, Okky Agassy Firmansyah, Sri Inang Sunaryati, and Nurman Rajagukguk \\ Center for Technology of Safety and Radiation Metrology (PTKMR) BATAN \\ Jl. Lebak Bulus Raya, Jakarta Selatan, 12440
}

\begin{abstract}
This paper describes the evaluation of well-type chamber calibration factor for measurement Ir192 brachytherapy source. Data were collected at ten institutions of Ir-192 brachytherapy facilities. Calibration was carried out using the substitution method adopted from a protocol published by the International Atomic Energy Agency. The well-type chamber standard used was HDR-1000 Plus. The results obtained that NAKS for well-type chamber from PTW manufacturers has a range of values from $9.063 \times 10^{5}-9.875 \times 10^{5} \mathrm{~Gy} \mathrm{~m}^{2}$ $\mathrm{h}^{-1} \mathrm{~A}^{-1}$ with an average value $9.522 \times 10^{5} \mathrm{~Gy} \mathrm{~m}^{2} \mathrm{~h}^{-1} \mathrm{~A}^{-1}$, while the well-type chamber from Standard Imaging manufacturers has a range of values from $4.634 \times 10^{5}-4.662 \times 10^{5} \mathrm{~Gy} \mathrm{~m}^{2} \mathrm{~h}^{-1} \mathrm{~A}^{-1}$ with an average value $4.648 \times 10^{5} \mathrm{~Gy} \mathrm{~m}^{2} \mathrm{~h}^{-1} \mathrm{~A}^{-1}$. The range of deviations obtained between $\mathrm{N}_{A K S-\text { new }}$ and $\mathrm{N}_{A K S-\text { old }}$ ranges from $0.8 \%$ to $-1.8 \%$, while the range of normalization results of $\mathrm{N}_{A K S-\text { new }}$ to the average value of $\mathrm{N}_{A K S-\text { new }}$ ranges from 0.952-1.029. There was one calibration factor that has a deviation of more than $1 \%$ over the $\mathrm{N}_{A K S-\text { old }}$. Based on the calculation of uncertainty, all the calibration factor results obtained were still within the accepted range.
\end{abstract}

Keywords: air Kerma strength; brachytherapy; calibration factor; well-type chamber

*Corresponding author: oafirmansyah@gmail.com

http://dx.doi.org/10.12962/j24604682.v16i2.6406

2460-4682 (C)Departemen Fisika, FSAD-ITS

\section{INTRODUCTION}

The use of brachytherapy modalities for cancer treatment has been used for more than 120 years in the world [1]. History records that the first clinical case handled by brachytherapy is a case with gynecologic cancer patients [2]. The development of brachytherapy initially used a radium source, then developed in the presence of artificial radiation sources such as Co-60, Cs-137, and Ir-192 [3].

In Indonesia, the use of brachytherapy modalities for cancer treatment has also developed quite rapidly. Some research references regarding the modality of brachytherapy have also been carried out by Indonesian researchers [4][7]. The most commonly used isotope as a radiation source was Ir-192, which has a half-life of 73,825 days with an average energy of $350 \mathrm{keV}$. In addition to Ir-192, some hospitals use Co-60 radiation sources, which have a half-life of 5.27 years with an average energy of $1250 \mathrm{keV}$ [8].

There were several protocols in dosimetry for brachytherapy that have been published such as those published by the International Atomic Energy Agency (IAEA) namely IAEA TEC-DOC No. 1079 which was later revised to IAEA TECDOC No. 1274, or AAPM TG-56 published by the American Association of Physicists in Medicine (AAPM). Several methods were available for measuring brachytherapy sources, namely free in air measurement and measurements using a well-type ionization detector [9][12]. Free in air measurement, use a standard ionization chamber $0.6 \mathrm{~cm} 3$ with a seven-distance measurement method[13]. In several publications, the well-type chamber was the recommended ionization chamber due to several advantages [10], [14], [15]. This well-type chamber can measure the source of brachytherapy in terms of air Kerma strength (AKS) [16].

Until the end of 2019, there were about fourteen hospitals using brachytherapy modalities to treat cancer. Ten of them use the Ir-192 source as a source of brachytherapy. The brachytherapy and dosimeter used were from several manufacturers. The dosimeter used also has various calibration factors and traceability from several calibration laboratories or from the manufacturer certificate.

The use of brachytherapy modalities in Indonesia was regulated through the Head of Nuclear Energy Regulatory Agency of Indonesia (BAPETEN), which one of the rules requires the hospital to calibrate the radiation sources of the brachytherapy and its dosimeters [17]. The purpose of this regulation was to guarantee the safety and health of ionizing radiation [18]. Based on these regulations, every hospital in 2019 was required to calibrate dosimeters for brachytherapy every year. The urgency of the calibration radiation measuring instrument calibration is to ensure the quality of service in accordance with established quality requirements.

This paper discusses the evaluation of the value of the calibration factor in terms of the air Kerma strength $\left(\mathrm{Gy} \mathrm{m}^{2} \mathrm{~h}^{-1}\right.$ $\mathrm{A}^{-1}$ ) from ten hospitals in Indonesia that use the modality of Ir-192 brachytherapy. The purpose of this study was to determine the range of calibration factor values based on the brand 
TABLE I: Initials Name of hospital, afterloading machine, and dosimeter used.

\begin{tabular}{llll}
\hline \hline Name & \multicolumn{1}{c}{ Detector/sn } & \multicolumn{1}{c}{ Brachytherapy } & \multicolumn{1}{c}{ Electrometer } \\
\hline RS-A & PTW TM 33002/000582 & Nucletron microSelectron PTW Unidos E T10008/081016 \\
RS-B & PTW TM 33004/000425 & Nucletron microSelectron PTW Unidos E T10008/082013 \\
RS-C & PTW TM 33004/000626 & Nucletron microSelectron PTW Unidos E T10008/082207 \\
RS-D & PTW TM 33005/121678 & Nucletron microSelectron PTW Unidos E T10008/082013 \\
RS-E & PTW TM 33004/000473 & Nucletron microSelectron PTW Unidos E T10008/081109 \\
RS-F & PTW TM 33005/121679 & Nucletron microSelectron PTW Unidos E T 10008/082217 \\
RS-G & REF 077094/00521 & Nucletron microSelectron PTW Tandem T 411013/0565 \\
RS-H & TM 33005/122055 & Nucletron microselectron PTW Unidos E T 10009/081109 & PTW Un \\
RS-I & HDR 1000 Plus/A111861 & Gamma Med Plus IX & Standard Imaging CDX 2000 B \\
& & & REF 90001/B 111399 \\
RS-J & HDR 1000 Plus/A111863 & Gamma Med Plus IX & \multicolumn{1}{l}{ Standard Imaging CDX 2000 B } \\
& & & REF 90001/B111396 \\
\hline \hline
\end{tabular}

TABLE II: The Result of calibration in terms of air Kerma strength $\left(10^{5} \mathrm{~Gy} \mathrm{~m}^{2} \mathrm{~h}^{-1} \mathrm{~A}^{-1}\right)$.

\begin{tabular}{|c|c|c|c|}
\hline Initial Name & $\mathbf{N}_{A K S-o l d}$ & $\mathbf{N}_{A K S-n e w}$ & Average $\mathbf{N}_{A K S}$ \\
\hline RS-A & 9.812 & 9.670 & \\
\hline RS-B & 9.742 & 9.729 & \\
\hline RS-C & 9.667 & 9.724 & \\
\hline RS-D & 9.143 & 9.175 & 9.522 \\
\hline RS-E & 9.778 & 9.731 & \\
\hline $\mathrm{RS}-\mathrm{F}$ & 9.138 & 9.063 & \\
\hline RS-G & 9.875 & 9.796 & \\
\hline RS-H & 9.117 & 9.286 & \\
\hline RS-I & 4.646 & 4.662 & 4.648 \\
\hline RS-J & 4.646 & 4.634 & \\
\hline
\end{tabular}

of the manufacturer device and evaluating the difference of the calibration factor compared to the calibration factor from the manufacturer.

The names of the hospitals that participated in this study were Murni Teguh Memorial Hospital Medan, Andalas University Hospital Padang, General Hospital Dr. Sardjito Yogyakarta, Regional General Hospital Prof. Dr. Margono Soekarjo Purwokerto, National General Hospital Dr. Cipto Mangunkusumo Jakarta, Dharmais Cancer Hospital Jakarta, General Hospital dr. Hasan Sadikin Bandung, General Hospital Dr. Soetomo Surabaya, Siloam Semanggi MRCCC Hospital Jakarta. To maintaining the confidentiality data, the name of the hospital will be changed to the alphabet (A-I) in this paper. The order of naming was not the same as the order mentioned above.

\section{MATERIALS AND METHOD}

\section{A. MATERIALS}

\section{Brachytherapy source}

The Brachytherapy source used was an Ir-192. Ten afterloading machines were consisting of eight Nucletron microS- electron afterloading machines (Elekta Instrument AB, Stockholm, Sweden) and two GammaMedPlusTM IX machines (Variant Medical System, Palo Alto, California). The list of brachytherapy afterloading machines used can be seen in Table I.

\section{Well-type chamber}

A well-type chamber was used as a radiation measurement detector for brachytherapy modalities. A well-type chamber was more recommended than a $0.6 \mathrm{~cm}^{3}$ farmer type ionization chamber, which significantly contributed to the scattering factor. The scattering factor was very influential in the absolute measurement of the brachytherapy. Some references state the contribution of scattering from $1 \%$ to $5.4 \%$ of the measured dose value [19], [20].

The standard well-type chamber for brachytherapy used by PTKMR-BATAN was the HDR-1000 Plus/A152152 welltype chamber made by Standard Imaging which was connected to the PTW Unidos Webline T10022/268 electrometer. This radiation measuring instrument was calibrated in terms of air Kerma strength at the University of Wisconsin Accredited Dosimetry Calibration Laboratory traced to the National Institute of Standards and Technology (NIST) with a calibration factor $\mathrm{N}_{A K S}=4,690 \times 10^{5} \mathrm{~Gy} \mathrm{~m}^{2} \mathrm{~h}^{-1} \mathrm{~A}^{-1}$ [24]. This well-type chamber was kept stable in the range $0.5 \%$ of deviation according to recommendations [21], [22].

The well-type chamber used by hospitals can be seen in Table II. This well-type has different specifications. Based on Table 2, in general, the well-type chamber used can be divided into twonamely, a well-type chamber made by Standard Imaging, USA, and made by PTW, Germany.

PTW SourceCheck 4 was a well-type chamber made by PTW Germany. This detector has a volume of $116 \mathrm{~cm} 3$ with a nominal response for the Ir-192 $125 \mathrm{fA} / \mathrm{MBq}$ source. The operating voltage of this detector was at $400 \mathrm{~V}$. This ionization detector has an inner diameter of $32 \mathrm{~mm}$ and weighs $1.4 \mathrm{~kg}$. The measurement reference point was $87 \mathrm{~mm}$ from the detector surface. For applications in the measurement of brachytherapy sources, this detector was equipped with several types of adapters for several types of afterloading machines and brachytherapy sources. Examples of these types 
of adapters were the universal HDR adapter T33004.1.013 for transfer tube diameter $1.8-3.2 \mathrm{~mm}$ and the universal adapter HDR T33004.1.012 for transfer tube diameter 1.0-1.8 mm.

The well-type chamber used by several hospitals was the HDR 1000 Plus well-type chamber made by Standard Imaging, USA. This well-type chamber has a nominal response of $2.1 \mathrm{pA} / \mathrm{Gy} \cdot \mathrm{m}^{2}$.A. $\mathrm{h}^{-1}$. Unlike the PTW SourceCheck $4 \pi$, the HDR 1000 Plus well-type has a volume of $245 \mathrm{~cm}^{3}$ with an operating voltage of $300 \mathrm{~V}$. This chamber was also equipped with several kinds of adapters intended for measurement of Ir-192, Co-60 and Cs-137 for high dose rates (HDR) or low dose rate (LDR).

To maintain the traceability re-calibration can be done in several National Metrology Institute (NMI) [23], whereas for Co-60 brachytherapy radiation sources currently only available in Germany's primary PTB laboratory [24].

\section{B. METHOD}

\section{Calibration well-type chamber using reference well-type chamber}

For secondary standard dosimetry laboratory (SSDL) with limited capabilities, calibration of a well-type chamber using a standard source was not easy to implement. It was due to the short half-life ( $\mathrm{T}(1 / 2)$ of the Ir-192 source which requires the laboratory to replace this source four times a year, and the availability of primary standard chamber used to standardize the source in terms of RAKR or SK has not been fulfilled.

To solve this problem, an alternative that can be applied was to use a substitution calibration method. The method has meant that a standard well-type chamber and hospital welltype chamber was irradiated alternately using an Ir-192 source owned by the hospital. This substitution method was adopted from the calibration procedure for dosimeters for radiotherapy published by the IAEA. With this method, the charge reading collected by the two detectors after some corrections were compared. The calibration factor value of the calibrated detector can be stated as follows [21][25]:

$$
N_{A K S}=\frac{M_{s t d} N_{A K S s t d} K_{P T}}{M K_{P T}}
$$

where, $\mathrm{N}_{A K S}$ : The value of calibration factor in terms of Kerma strength $\left(\mathrm{Gy} \mathrm{m} \mathrm{m}^{2} \mathrm{~h}^{-1} \mathrm{~A}^{-1}\right), \mathrm{M}_{s t d}$ : Reading of Welltype chamber standard (nC), $\mathrm{N}_{A K S s t d}$ : Calibration factor of well-type chamber standard $\left(\mathrm{Gy} \mathrm{m} \mathrm{m}^{2} \mathrm{~h}^{-1} \mathrm{~A}^{-1}\right)$, M: Reading of Well-type chamber user ( $\mathrm{nC}), \mathrm{K}_{P T}$ : Correction factor for temperature and pressure $\left(\mathrm{K}_{P T}\right)$.

The substitution method's disadvantage was the more considerable uncertainty of the calibration results than calibration using the standard source method. Besides, that calibration must be done in the user/hospital place (on-site) using the hospital's radiation source.

Measurement of charged particles by chamber was influenced by external factors, namely temperature, and pressure
[26]. The correction factors for temperature and room air pressure were calculated using the formula [21].

$$
K_{P T}=\frac{273.15+T}{273.15+T_{\circ}} \times \frac{P_{\circ}}{P}
$$

where, $\mathrm{K}_{P T}$ : Correction factor for temperature and pressure, T: Temperature reading $\left({ }^{\circ} \mathrm{C}\right), \mathrm{T}_{\circ}$ : Temperature reference $\left(20^{\circ} \mathrm{C}\right), \mathrm{P}$ : Pressure reading $(\mathrm{kPa}), \mathrm{P}_{\circ}$ : Pressure reference $(\mathrm{kPa})$.

Calibration measurements were carried out by placing the detector on a custom wooden table in the center of the brachytherapy room with a distance of one meter from each wall and one meter from the floor. This setting aimed to reduce the scattering effect [15], [21], [27]. Fig. 1 shows the measurement setting of different machine, namely, Nucletron microSelectron and Gamma Med Plus IX. The different measurement settings due to both of the machines have geometry size, a few modifications needed to apply. It is also an adjustment for positioning the catheter/transport tube to the welltype chamber adapter. Fig. 2 shows the different geometry of the well-type chamber and its adapter.

\section{Maximum response measurement of well-type chamber}

The air Kerma strength measurement using a well-type chamber was done at the maximum point of measurement. Due to get the maximum point of measurement in a well-type chamber, scanning must be performed [14].

The scanning was performed to obtain the maximum response position from the reading of the Ir-192 source in the well-type chamber [24], [28]. At the scanning process, the amount read on the electrometer was the current (nA). Scans were carried out in each step by the system software. Wait until the maximum response position was obtained. Then the measurement of the air Kerma strength was done with five repeated measurement data. Temperature and pressure conditions in the room were also calculated as correction of temperature and pressure (KPT).

\section{Measurement of air Kerma strength}

The measurement of air Kerma strength was carried out with a standard HDR-1000 Plus/A152152 well-type chamber connected to the PTW Unidos Webline T1002/268 at the position of the radiation source with a maximum response for one minute irradiation time. After the measurement data was obtained, the substitution was carried out on a standard well-type chamber with the hospital's well-type chamber.

\section{RESULTS AND DISCUSSION}

\section{A. Result}

Fig. 3 was an example of one of the results of scanning the maximum position of the Ir-192 source measurement on a well-type chamber. The red graph was the result of a 


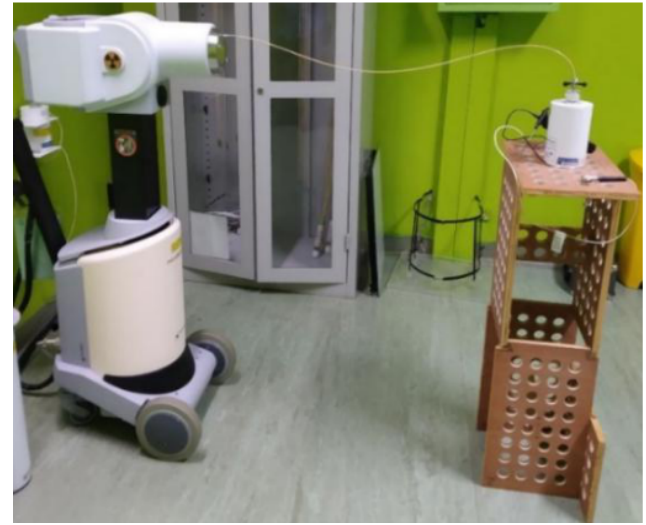

(a)

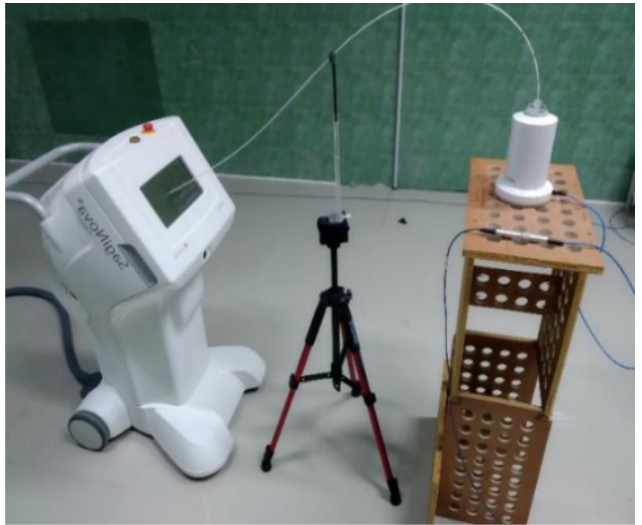

(b)

FIG. 1: Calibration setting on the custom wooden table and (a) Nucletron microSelectron afterloading machine (b) Gamma Med Plus IX afterloading machine.

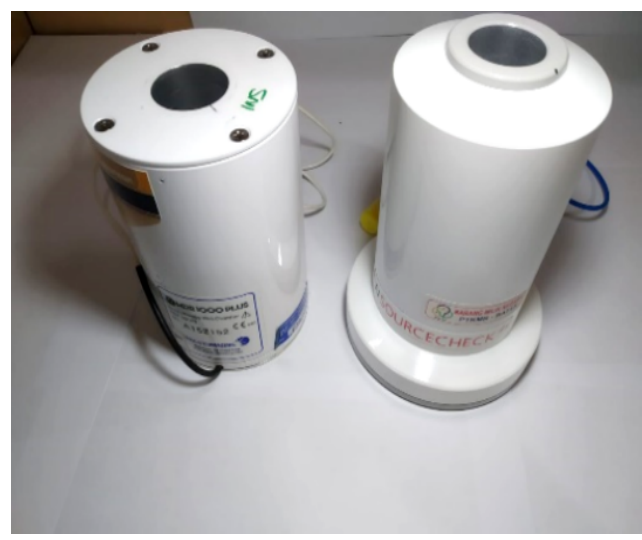

(a)

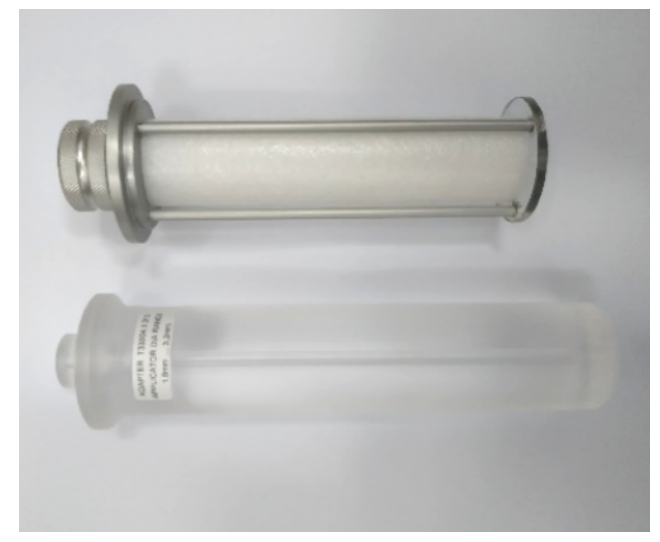

(b)

FIG. 2: (a) (left-side) Well-type chamber PTW SourceCheck 4, (right-side) Well-Type chamber HDR1000Plus (b) Adapter for transport tube.

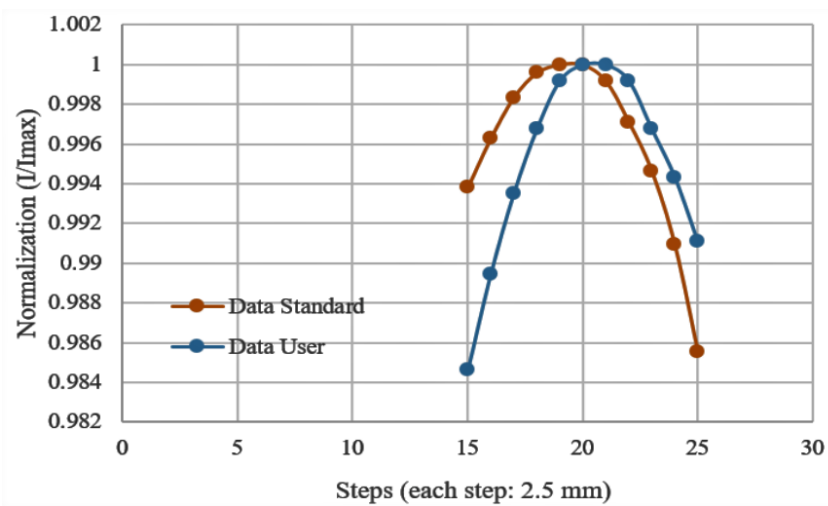

FIG. 3: The Result of scanning maximum response.

graph from measurements using the standard well-type chamber (BATAN), while the blue graph was data from measurements using the hospital's well-type chamber. The raw data from these measurements was current reading (nA). These re- sults have been normalized to the maximum current value of each electrometer reading of the well-type chamber.

It can be seen that the maximum measurement position on the standard detector was obtained in step 19, while the maximum measurement position for hospital detector was obtained at step 20. The distance per step on the Nucletron microSelectron afterloading machine used was $2.5 \mathrm{~mm}$. Based on this maximum point, the calibration of the well-type chamber was carried out by the substitution method. Here the result from calibration in terms of air Kerma strength calibration factor (NAKS-new) can be seen in Table II.

The classification of the calibration factor $\left(\mathrm{N}_{A K S}\right)$ in Table II was based on the type of afterloading machine and detectors used by the hospital. It can be seen that the calibration factor in the terms of air Kerma Strength $\left(\mathrm{N}_{A K S}\right)$ for detectors from PTW manufacturers has a range from $9,063 \times 10^{5}-9,875 \times$ $10^{5} \mathrm{~Gy} \mathrm{~m}^{2} \mathrm{~h}^{-1} \mathrm{~A}^{-1}$ with an average value of $9.522 \times 10^{5} \mathrm{~Gy}$ $\mathrm{m}^{2} \mathrm{~h}^{-1} \mathrm{~A}^{-1}$, whereas The detector from the manufacturer of Standard Imaging has a range from 4,634 × $10^{5}-4,662 \times 10^{5}$ Gy $\mathrm{m}^{2} \mathrm{~h}^{-1} \mathrm{~A}^{-1}$ with an average value of $4,648 \times 10^{5} \mathrm{~Gy} \mathrm{~m}^{2}$ 


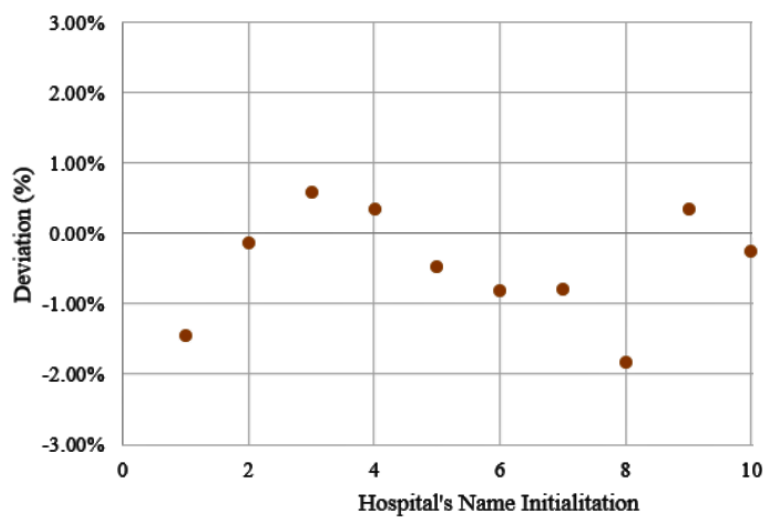

FIG. 4: Percentage result of deviation between $\mathrm{N}_{A K S-n e w}$ and $\mathrm{N}_{A K S-\text { old }}$.

$\mathrm{h}^{-1} \mathrm{~A}^{-1}$.

There was a deviation in the acquisition of the calibration factor $\left(\mathrm{N}_{A K S-\text { new }}\right)$ value with the manufacturer's calibration factor $\left(\mathrm{N}_{A K S-o l d}\right)$. The range of deviations obtained between $\mathrm{N}_{A K S-\text { new }}$ and $\mathrm{N}_{A K S-\text { old }}$ ranges from $0.8 \%$ to $-1.8 \%$. The data distribution of the percentage deviations was illustrated in Fig. 4.

Fig. 4 explains the distribution of normalized data from $\mathrm{N}_{A K S-\text { new }}$ to the average value of $\mathrm{N}_{A K S-\text { old }}$ obtained from the calibration results. The range of normalization results of $\mathrm{N}_{A K S-n e w}$ against the average value of $\mathrm{N}_{A K S-\text { old }}$ ranges from 0.952-1.029. Normalization was done to see the distribution of data from all $\mathrm{N}_{A K S-\text { new }}$ obtained against the average value.

\section{B. Discussion}

Before measuring with a well-type chamber, scanning for the maximum response was done at an early step. The data plot shows the results corresponding to each volume of the well-type chamber. In data collection for scanning (Fig. 3), the hospital detector used was the PTW manufacturer, which has a volume of $116 \mathrm{~cm}^{3}$, while BATAN uses the Standard Imaging well-type chamber, which has a volume of $245 \mathrm{~cm}^{3}$. This difference in volume results in different responses as well as reference points of measurement.

Another factor that influences the scanning results of the well-type chamber was the type of afterloading machine. Each type of afterloading machine has several transfer tubes according to clinical needs and dosimetry, which have different lengths. This transfer tube was used to transport source transfers from the afterloading machine to the brachytherapy applicator. An example was the transfer tube with LAF1000 type belonging to the Gamma Med IX afterloading machine with a length of $1000 \mathrm{~cm}$.

For dosimetry needs with a well-type chamber, the length of initialization in the treatment planning system (TPS) influences whether or not the transfer tube setting for the detector was accepted. The setting at the time of measurement us-

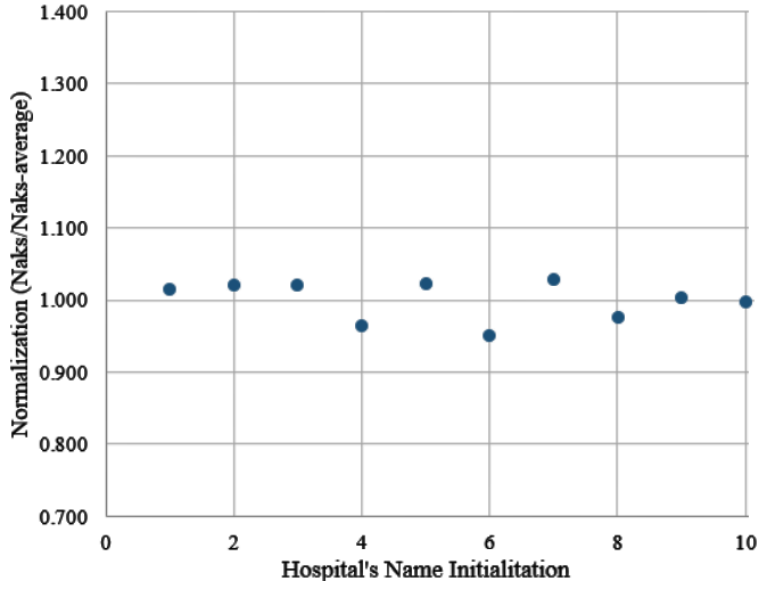

FIG. 5: Result of normalized calculation against $\mathrm{N}_{K S}$ average.

ing the HDR1000Plus well-type chamber was different from PTW SourceCheck 4. For BATAN's HDR1000Plus detector, the initialization length of the system was identified by the length of the transfer tube plus $14 \mathrm{~cm}$ for the initialization of the plastic catheter used, whereas for PTW SourceCheck $4 \pi$ detectors can be directly identified according to the transfer tube used.

The choice of channel and different step sizes also affect the location of the maximum measurement. Each afterloading machine has a different step range. Some afterloading machine uses a size of $2.5 \mathrm{~mm}$ per step and $5 \mathrm{~mm}$ per step (default condition).

Table II shows the results of $\mathrm{N}_{A K S}$ calibration using a standard well-type chamber. Based on these results, it was known that the $\mathrm{N}_{A K S}$ range was the result of calibration. The range can be used as a reference for future calibration of a well-type chamber.

The percentage of deviation in the acquisition of the calibration factor $\left(\mathrm{N}_{A K S-n e w}\right)$ with a calibration factor from the manufacturer $\left(\mathrm{N}_{A K S-\text { old }}\right)$ was known to show quite good results even though some measurements have deviations above $1 \%$. These results meet the requirements of the quality assurance applied by BATAN that the calibration results were maintained within a deviation range of less than $1 \%$.

Obtaining a deviation of more than $1 \%$ was possible due to differences in conditions in measurements between the primary laboratory/manufacturer and the actual conditions. The measurement conditions at the primary/manufacturer's laboratory were set to approach the ideal measurement, i.e., measurements with low scattering, while the actual measurements made by BATAN have not met ideal conditions. This condition can be caused by the size of the brachytherapy room, which has a variety of sizes, as well as the number of supporting components of brachytherapy facilities made of iron/metal placed in the room so that it was probable that the facility also contributes to the scattering of measurements. Based on the literature, placing the well-type chamber close to the wall will contribute a reading of currents ranging from $1 \%$ higher than it should be [29]. 
By the reference, the well-type chamber must be placed at a minimum distance of one meter from the walls and floor, and supporting facilities were also minimized from objects made of iron/metal, and stabilization of the well-type chamber was carried out the day before the measurement performed in the treatment room [30].

The calibration of the well-type chamber independently needs to be done periodically to meet the quality assurance requirements of the dosimetry measurements. In addition to recalibration, aspects of quality assurance that can be met regularly were stability checks. The stability of the detector must be maintained in the range of $\pm 5 \%$. Stability checks can be carried out using the Am-241 sources for low-energy photons, while for high-energy photons, a Cs-137 or Co-60 source [21].

\section{UNCERTAINTY OF MEASUREMENT}

The uncertainty of the measurement results was evaluated according to the criteria contained in ISO/TAG 4/WG 3: Guide to the Expression of Uncertainty in Measurement which defines two categories of uncertainty components namely Type A and Type B [31]. Uncertainty components of type A include repeated readings of well-type chamber standard and repeated readings of the calibrated well-type chamber, while type B include: uncertainty of stability of swell-type chamber standard, changes in source position, calibration factors of well-type chamber standard, barometers, thermometer.

Evaluation of measurement uncertainty based on the uncertainty component mentioned above obtained an expanded uncertainty of $\pm 3.0 \%$. Based on the uncertainty range obtained for determination of acceptable air Kerma strength was 5\%, while the acceptable accuracy of calibration results was $\pm 3 \%$ of air Kerma strength measured by the manufacturer [32].

\section{CONCLUSIONS}

Based on the results and discussion, it can be concluded that in-situ calibration of the well-type chamber at ten hospi- tal institutions gets a calibration factor that was still within the acceptable uncertainty range. The results obtained show that $\mathrm{N}_{A K S}$ for detectors from PTW manufacturers have a range of values from $9,063 \times 10^{5}-9,875 \times 10^{5} \mathrm{~Gy} \mathrm{~m}^{2} \mathrm{~h}^{-1} \mathrm{~A}^{-1}$ with an average value of $9.522 \times 10^{5} \mathrm{~Gy} \mathrm{~m}^{2} \mathrm{~h}^{-1} \mathrm{~A}^{-1}$, while welltype chamber from Standard Imaging manufacturers have a range of values from $4,634 \times 10^{5}-4,662 \times 10^{5} \mathrm{~Gy} \mathrm{~m}^{2} \mathrm{~h}^{-1}$ $\mathrm{A}^{-1}$ with an average value of $4,648 \times 10^{5} \mathrm{~Gy} \mathrm{~m}^{2} \mathrm{~h}^{-1} \mathrm{~A}^{-1}$. The range of deviations obtained between $\mathrm{N}_{A K S-n e w}$ and $\mathrm{N}_{A K S-\text { old }}$ ranges from $0.8 \%$ to $-1.8 \%$, while the range of normalization results of $\mathrm{N}_{A K S-n e w}$ against the average value of $\mathrm{N}_{A K S-n e w}$ ranges from 0.952-1.029. There was one calibration factor that has a deviation of more than $1 \%$ over the $\mathrm{N}_{A K S-o l d}$.

Measurement of Ir-192 brachytherapy sources was better carried out in minimal room conditions for scattering. The minimization of the scattering effect can be done by conditioning the minimal space to iron/metal objects and laying a well-type chamber in the center of the room with a minimum distance of one meter from the walls and floor.

\section{Acknowledgments}

The author would like to acknowledge the staff of Murni Teguh Memorial Hospital Medan, Andalas University Hospital Padang, Central General Hospital Dr. Sardjito Yogyakarta, Regional General Hospital Prof. Dr. Margono Soekarjo Purwokerto, National General Hospital Dr. Cipto Mangunkusumo Jakarta, Dharmais Cancer Hospital Jakarta, General Hospital dr. Hasan Sadikin Bandung, General Hospital Dr. Soetomo Surabaya, Siloam Semanggi MRCCC Hospital Jakarta for help and corporation so that this paper can be completed.
[1] G. Kemkler, "History of Brachytherapy", Turkish J. Oncol., vol. 34, no. 1, pp. 110, 2019.

[2] J.N. Aronowitz, S.V. Aronowitz, and R.F. Robison, "Classics in Brachytherapy: Margaret Cleaves Introduces Gynecologic Brachytherapy", Brachytherapy, vol. 6, pp. 293297, 2007.

[3] J.F. Williamson, "Brachytherapy technology and physics practice since 1950: a half-century of progress", Phys. Med. Biol, vol. 51, pp. 303325, 2006.

[4] I. Hasan, and I. Ramli, "Brakhiterapi Nasofaring", J. Indones. Radiat. Oncol. Soc., vol. 5, no. 2, pp. 7784, 2014.

[5] A. Suntoro, "Analisis Proses Pengambilan Data Pada Rekontruksi Koordinat untuk Treatment Planning System (TPS) Brakiterapi Kanker Servik", Apl. dan Rekayasa dalam Bid. Iptek Nukl., vol. 9, no. November, pp. 6978, 2012.

[6] A.J. Petrarizky, and I. Ramli, "Brakiterapi High Dose Rate dan Low Dose Rate dari Sisi Radiobiologi”, J. Indones. Radiat. Oncol. Soc., vol. 3, no. January, pp. 813, 2012.
[7] M.R. Putra, D. Milvita, and H. Prasetio, "Karakterisasi Dosimetri Sumber Brakiterapi Ir-192 Menggunakan Metode Absolut”, J.Fis. Univ.Negeri Padang, vol. 4, no. 2, hlm. 129135, 2015.

[8] N. Rajagukguk, and A.F. Firmansyah, "Komunikasi pribadi dengan fisikawan medis RS Murni Teguh Memorial Hospital, RSUD Moewardi, RSUD Sanglah, RS Bandung Kopo, RS Kanker Dharmais, RSUPN Dr. Cipto Mangunkusumo, RSUD Dr. Sardjito, RS Universitas Andalas dan RSUD Prof. DR Margono Soekarjo", 2019.

[9] N.F.S.N. Azmi, A. Zakaria, R. Abdullah, and N.A. Hadi, "Comparison QA methods of brachytherapy using well ionization chamber and in-air method", Malaysian J. Fundam. Appl. Sci., vol. 8, no. 5, pp. 246252, 2012.

[10] S. Bondel, M. Ravikumar, and S.S. Supe, "Calibration of 192 Ir high dose rate brachytherapy source using different calibration procedures", Reports Pract. Oncol. Radiother., vol. 19, no. 3, 
pp. 151156, 2014.

[11] M. A. Gadhi, S.A. Buzdar, M. Afzal, S. Fatmi, M.S. Akhtar, and A.H. Nizamani, "Calibration of iridium-192 source by ionization chamber for high dose rate brachytherapy", vol. 11, no. 3, 2013.

[12] L.C.S. Ho, and T.L.H. Ding, ”Ir-192 Calibration in Air with Farmer Chamber for HDR Brachytherapy, J. Med. Biol. Eng., vol. 36, no. 2, pp. 145152, 2016.

[13] S. B. Ondel and M. R. Avikumar, Determination of contributions of scatter and distance error to the source strength of $192 \mathrm{Ir}$ HDR brachytherapy source", vol. 22, no. September, pp. 5559, 2016.

[14] S. Vandana, and S.D. Sharma, "Long term response stability of a well-type ionization chamber used in calibration of high dose rate brachytherapy sources", J. Med. Phys., vol. 35, no. 2, pp. $100103,2010$.

[15] H.A. Azhari, F. Hensley, W. Schtte, and G.A. Zakaria, "Dosimetric verification of source strength for HDR afterloading units with Ir-192 and Co-60 photon sources: Comparison of three different international protocols", J. Med. Phys., vol. 37, no. 4, pp. 183192, 2012.

[16] R. Nath, L.L. Anderson, J.A. Meli, A.J. Olch, J.A. Stitt, and J.F. Williamson, "Code of practice for brachytherapy physics: Report of the AAPM Radiation Therapy Committee Task Group No . 56", 1997.

[17] Badan Pengawas Tenaga Nuklir, "Peraturan Kepala BAPETEN No. 1 tahun 2006 tentang Laboratorium Dosimetri, Kalibrasi Alat Ukur Radiasi dan Keluaran Sumber Radiasi, Terapi, dan Standardisasi Radionuklida", 2006.

[18] Pemerintah Republik Indonesia, "Peraturan Pemerintah No.63 Tahun 2000 tentang Keselamatan dan Kesehatan Kerja Terhadap Radiasi Pengion", 2000.

[19] N.P. Patel, B. Majumdar, and V. Vijayan, "Study of scattered radiation for in-air calibration by a multiple- distance method using ionization chambers and an HDR 192 Ir brachytherapy source”, Br. J. Radiol., vol. 79, no. October, pp. 347352, 2006.

[20] S. Bondel and M. Ravikumar, "Determination of contributions of scatter and distance error to the source strength of $192 \mathrm{Ir}$ HDR brachytherapy source", J. Med. Phys. Eng., vol. 22, no. September, pp. 5559, 2016.

[21] International Atomic Energy Agency, "IAEA-TECDOC-1274: Calibration of photon and beta ray sources used in brachytherapy", 2002.
[22] S.L. Hackett, B. Davis, A. Nixon, and R. Wyatt, "Constancy checks of well-type ionization chambers with external-beam radiation units", J. Appl. Clin. Med. Phys., vol. 16, no. 6, pp. 508514, 2015.

[23] C.G. Soares, G. Douysset, and M. Mitch, "Primary standards and dosimetry protocols for brachytherapy sources", Metrologia, vol. 46, pp. S80S98, 2009.

[24] A. Schller, et al., "A radiation quality correction factor kQ for well-type ionization chambers for the measurement of the reference air Kerma rate of 60Co HDR brachytherapy sources A radiation quality correction factor $\mathrm{kQ}$ for well-type ionization chambers for the measurement,", vol. 4285, 2015.

[25] IAEA, "IAEA TRS 469: Calibration of Reference Dosimeters for External Beam Radiotherapy”, 2009.

[26] T.D. Bohm, et al., "The effect of ambient pressure on well chamber response: Monte Carlo calculated results for the HDR 1000 Plus The effect of ambient pressure on well chamber response: Monte Carlo calculated results for the HDR 1000 Plus"., vol 1103, no. 2005, 2009.

[27] C.E. de Almeida, et al., "Intercomparison of calibration procedures for 192 Ir HDR sources in Brazil”, Phys. Med. Biol, vol. 444, pp. 3138, 1999.

[28] A.M. Bidmead, et al., "The IPEM code of practice for determination of the reference air Kerma rate for HDR Ir-192 brachytherapy sources based on the NPL air Kerma standard The IPEM code of practice for determination of the reference air Kerma rate for HDR 192Ir brachytherapy so", Phys. Med. Biol, vol. 55, pp. 31453159, 2010.

[29] M.B. Podgorsak, L.A. DeWerd, B.R. Thomadsen, and R.B. Paliwal, "Thermal and scatter effects on the radiation sensitivity of well chambers used for high dose rate lr-192 calibrations", Med. Phys., vol. 19, no. 5, pp. 13111314, 1992.

[30] R. Abdullah, et al., "High dose rate 192 Ir source calibration: A single institution experience High dose rate 192 Ir source calibration: A single institution experience", in IOP Conf. Series: Journal of Physics: Conf. Series, 2017, pp. 16.

[31] BIPM, "JCGM 100:2008-Evaluation of measurement dataGuide to the expression of uncertainty in measurement", 2008.

[32] S. Saminathan, H.F. Godson, and R. Manickam, "Dosimetric evaluation of newly developed well-type ionization chamber for use in the calibration of brachytherapy sources", J. Med. Phys., vol. 41, no. November 2017, 2016. 